\title{
Depression and Anxiety in Patients with Chronic Renal Failure: The Effect of Sociodemographic Characteristics
}

\author{
Paraskevi Theofilou \\ Department of Psychology, University of Panteion, Eratous 12, 14568 Athens, Greece \\ Correspondence should be addressed to Paraskevi Theofilou, theofi@otenet.gr \\ Received 24 January 2011; Accepted 31 March 2011 \\ Academic Editor: Hulya Taskapan
}

Copyright () 2011 Paraskevi Theofilou. This is an open access article distributed under the Creative Commons Attribution License, which permits unrestricted use, distribution, and reproduction in any medium, provided the original work is properly cited.

"Do the sociodemographic characteristics relate to the levels of depression and anxiety in patients with chronic renal failure in Athens?" The study investigated in a group of renal disease patients differences referring to self-reported mental health, depression, and anxiety, after controlling for gender, age, education, and marital status. Patient-reported assessments included General Health Questionnaire (GHQ-28) of Goldberg, Center for Epidemiological Studies Depression Scale (CES-D), and State-Trait Anxiety Inventory (STAI I \& II) of Spielberger. Female patients reported higher scores in the trait anxiety measure. Elder patients reported higher scores in the GHQ-28 subscale of social dysfunction and in the CES-D depression scale, while less educated patients presented higher scores in the GHQ-28 subscales of anxiety/insomnia and severe depression. Divorced/widowed patients presented higher scores in the severe depression subscale. Findings provide evidence that sociodemographic variables, like being older, less educated, and divorced/widowed, relate to a more compromised mental health.

\section{Introduction}

Populations facing chronic illness have been reported to have poorer quality of life (QoL) and mental health, including higher levels of depression [1-5]. In this context, health services for ill-health populations, including chronic renal failure (CRF), have drawn attention to promotion of mental health issues [6-10]. It is worth noting that CRF is a disease with serious effects on the patients' QoL, negatively affecting their social, financial, and psychological well-being [11-14].

Regarding differences between the main methods of renal replacement therapy, that is haemodialysis (HD) and peritoneal dialysis (PD), HD patients have been found to experience more depressive symptoms than $\mathrm{PD}[9,11]$. Depression may be linked to the HD treatment modality, since the patient has to be continually connected to the haemodialysis machine during dialysis and so experience significant restrictions in independent living [10]. In addition, the rate of reported suicide in HD is higher, while a substantial number of deaths resulting from dietary violations could also be accounted for as suicide [10].

Furthermore, HD patients are reported to face psychosocial problems, which can contribute to conflictions between themselves and their medical carers. Such findings could be attributed in part to the stressful conditions in the HD treatment modality, including frequent visits and prolonged waiting time in the dialysis unit [12]. Regarding psychological dimensions in end-stage renal disease (ESRD), it seems that PD patients are better adjusted than HD. This may be due to the peritoneal treatment modality offering increased autonomy and control, flexibility in everyday life and the dietary regime, and fewer social restrictions [14]. PD patients have been found to report better QoL ratings in specific areas like "perceived ability to travel," "financial concerns", "restriction in eating and drinking," and "dialysis access problems" [12]. Furthermore, PD patients have indicated more positive ratings in several disease QoL domains, for example, less kidney disease burden, and being more encouraged and satisfied with care [12-14].

Regarding the effect of sociodemographic variables on patients' mental health, gender is reported to have an effect; so female patients present higher scores of depression and trait anxiety and lower scores in positive affect [15-18]. Male patients are reported of having more social activities and interests and better QoL $[15,19,20]$. 
TABLE 1: Sociodemographic characteristics of the sample $(N=$ 144).

\begin{tabular}{lcc}
\hline & $\begin{array}{c}\text { Male } \\
N=86(59.7 \%)\end{array}$ & $\begin{array}{c}\text { Female } \\
\text { Age (years) }\end{array}$ \\
Mean (SD) & $59.3 \%)$ \\
\hline Marital status & $59.90(16.88)$ & $61.84(11.68)$ \\
Single & $18(20.9 \%)$ & $7(12.1 \%)$ \\
Married & $65(75.6 \%)$ & $42(72.4 \%)$ \\
Divorced/Widowed/ & $3(3.5 \%)$ & $9(15.5 \%)$ \\
Roommate & $86(100 \%)$ & $58(100.0 \%)$ \\
\hline Total & & \\
\hline Education & $29(33.7 \%)$ & $33(56.9 \%)$ \\
Elementary & $35(40.7 \%)$ & $21(36.2 \%)$ \\
Secondary & $22(25.6 \%)$ & $4(6.9 \%)$ \\
University & $86(100.0 \%)$ & $58(100.0 \%)$ \\
\hline Total & &
\end{tabular}

Further, older patients present lower levels of physical well-being and higher scores of depression [17, 21-28]. Regarding the effect of socioeconomic status, patients in the lower range face many problems, including poorer mental and general health and lower social well-being [29, 30], whereas higher economic and educational level is associated with higher health-related QoL [19, 31]. Concerning marital status, being married is related to better physical well-being as well as emotional health [26].

In spite of the fact that several papers on mental health referring to patients with CRF have been published, the studies investigating the role of sociodemographic variables on mental health issues are limited, and the produced findings are frequently controversial. The aim of this study was to investigate in a total sample of chronic renal disease patients differences referring to self-reported mental health, depression, and anxiety after controlling for gender, age, levels of education, and marital status. These differences were also investigated in the groups of $\mathrm{HD}$ and $\mathrm{PD}$ patients separately.

The main hypothesis is that being male patient, younger, more educated, and married relates to a better mental health with less depressive and anxiety symptoms.

\section{Materials and Methods}

A sample of 144 patients was recruited from three general hospitals in the broader area of Athens, consisting of 84 patients $(58.3 \%)$ undergoing in-centre haemodialysis (HD) and 60 patients (41.7\%) in continuous ambulatory peritoneal dialysis (CAPD/PD). The rate of response was very high, reaching $99 \%$. Thus, the total sample includes almost all patients of these three units, consisting of 86 males $(59.7 \%)$ and 58 females (40.3\%), with a mean age of 60.6 years \pm 14.9 . Participants were Greek adults having signed a consent form for participation. All subjects had been informed of their rights to refuse or discontinue participation in the study according to the ethical standards of the Helsinki Declaration in 1983. Ethical permission for the study was obtained from the scientific committees of the hospitals. The period of the questionnaires given to the patients was between November 2007 and March 2008, while the study took place between October 2007 and June 2008. Full descriptive data of the sample are presented in Table 1.

The subjects (HD, PD) were selected according to the following criteria:

(1) diagnosis of end-stage renal disease,

(2) current HD or PD treatment,

(3) age above 18 ,

(4) native language, Greek,

(5) volunteer participation and signed consent form. ments

Measurements were conducted with the following instru-

(1) General Health Questionnaire (GHQ-28) version is a widely used self-report measure designed to detect psychiatric problems in general settings [32], which has been standardized in Greek populations [33]. It includes four subscales: (a) somatic symptoms, (b) anxiety/insomnia, (c) social dysfunction, and (d) severe depression. Higher scores indicate a worse general condition of health.

(2) Center for Epidemiologic Studies Depression Scale (CES-D) is a 20-item self-report measure of depression [34, 35]. According to Fountoulakis et al. [36], it is suggested that for Greek populations a value above 9.03 is indicative that a subject can be classified as depressed [36].

(3) State-Trait Anxiety Inventory (STAI I/STAI II). It consists of 20 items referring to self-reported state anxiety and 20 items to trait anxiety [37]. The instrument is standardized in Greek populations [38]. Higher scores indicate the presence of state and trait anxiety.

\section{Results}

The values of the two gender groups were found to pass the normality distribution, with the use of Kolmogorov-Smirnov $Z$ test. Investigating gender differences, female patients tended to report higher scores in the GHQ-28 subscale of severe depression $(P=.05)$ (Table 2). No statistically significant differences were found in depression measured by CES-D (Table 2). It is noteworthy that regarding this scale, with the use of the above-suggested cutoff point, both male and female patients present higher values and can be considered as depressed ( $M=11.94$ and 14.32, resp.). Further, women presented significantly higher scores than men in trait anxiety measured by STAI II.

Concerning age, statistically significant differences were found between younger ( $<45$ years) and older patients $(>45$ years). Specifically, older patients reported a significantly higher level of social dysfunction and depression (Table 3). 
TABLE 2: Mean scores \pm SD of GHQ-28 health subscales, depression and state-trait anxiety. Independent samples $t$-test demonstrating differences between men and women.

\begin{tabular}{lccc}
\hline & $\begin{array}{c}(N=86) \mathrm{Men} \\
M \pm \mathrm{SD}\end{array}$ & $\begin{array}{c}(N=58) \text { Women } \\
M \pm \mathrm{SD}\end{array}$ & $P$ value \\
\hline $\begin{array}{l}\text { GHQ-28 subscales } \\
\text { Somatic } \\
\text { symptoms }\end{array}$ & $1.73 \pm 0.50$ & $1.87 \pm 0.60$ & NS** \\
$\begin{array}{l}\text { Anxiety/insomnia } \\
\text { Social } \\
\text { dysfunction }\end{array}$ & $1.66 \pm 0.60$ & $1.78 \pm 0.72$ & $\mathrm{NS}$ \\
$\begin{array}{l}\text { Severe depression } \\
\text { Total score }\end{array}$ & $1.35 \pm 0.55$ & $1.62 \pm 0.86$ & $.05^{*}$ \\
\hline CES-D & & $1.91 \pm 0.58$ & $\mathrm{NS}$ \\
depression & $11.94 \pm 10.73$ & $14.32 \pm 12.56$ & $\mathrm{NS}$ \\
\hline $\begin{array}{l}\text { STAI } I \\
\text { state anxiety }\end{array}$ & $28.77 \pm 7.11$ & $32.39 \pm 12.22$ & $\mathrm{NS}$ \\
\hline $\begin{array}{l}\text { STAI } I I \\
\text { trait anxiety }\end{array}$ & $33.30 \pm 7.85$ & $38.21 \pm 10.14$ & $.01 *$ \\
\hline${ }^{*} P<.05 ; N=144$. & & & \\
$* *$ NS: not significant. & & &
\end{tabular}

Regarding education, less educated patients ( $<9$ years) reported significantly higher scores in the anxiety/insomnia and severe depression subscales as well as in the total GHQ-28 score (Table 4).

As far as marital status is concerned, divorced/widowed patients presented significantly higher scores in the GHQ-28 subscale of severe depression compared to singles and married (Table 5).

In the group of HD patients, females reported worse mental health with more somatic symptoms $(2.04 \pm 0.57$, $P=.04)$ and social dysfunction $(2.46 \pm 0.54, P=.05)$. Females also reported more trait anxiety $(39.45 \pm 7.73$, $P=.04)$ in comparison to males. With regards to age and marital status, older ( $>45$ years) and divorced/widowed HD patients presented higher level of depression (12.90 \pm 13.96, $35.50 \pm 4.95, P=.02)$. On the contrary, married HD patients reported better mental health $(1.84 \pm 0.49, P=.01)$, measured by GHQ-28 questionnaire.

In the group of PD patients, females presented more state anxiety $(33.55 \pm 10.28, P=.02)$. Concerning age, older $(>45$ years) PD patients presented more somatic symptoms $(1.72 \pm$ $0.53, P=.03)$ and social dysfunction $(2.25 \pm 0.40, P=.03)$ as well as more depression $(13.96 \pm 10.69, P=.00)$.

\section{Discussion}

Investigating the relationship of sociodemographic variables to mental health, female patients tended to evaluate less favourably their general condition of health and mental health as measured by GHQ-28. The tendency was to report being more depressed endorsing more suicidal thoughts than men. This finding is in agreement with several studies on chronic diseases, presenting female patients feeling more
TABle 3: Mean scores \pm SD of GHQ-28 health subscales and depression. Independent samples $t$-test demonstrating differences between the two categories of age.

\begin{tabular}{lccc}
\hline & $\begin{array}{c}(N=24) \\
\text { Age } \\
(<45 \text { years }) \\
M \pm \text { SD }\end{array}$ & $\begin{array}{c}(N=120) \\
\text { Age } \\
(>45 \text { years })\end{array}$ & $P$ value \\
& & & \\
\hline GHQ-28 subscales & & $1.79 \pm 0.55$ & NS** \\
Somatic symptoms & $1.76 \pm 0.55$ & $1.69 \pm 0.65$ & NS \\
Anxiety/insomnia & $1.81 \pm 0.63$ & $2.30 \pm 0.46$ & $.01^{*}$ \\
Social dysfunction & $2.04 \pm 0.45$ & $1.48 \pm 0.75$ & $\mathrm{NS}$ \\
Severe depression & $1.35 \pm 0.36$ & $1.82 \pm 0.51$ & $\mathrm{NS}$ \\
\hline Total score & $1.74 \pm 0.37$ & & \\
\hline CES-D & & & \\
Depression & $6.62 \pm 3.24$ & $13.58 \pm 11.89$ & $.00^{*}$ \\
\hline${ }^{*} P<.05 ; N=144$. & & & \\
$* *$ NS: not significant. & & &
\end{tabular}

TABle 4: Mean scores \pm SD of GHQ-28 health subscales. Independent samples $t$-test demonstrating differences between the two categories of education.

\begin{tabular}{lccc}
\hline GHQ-28 subscales & $\begin{array}{c}(N=87) \\
\text { Years of } \\
\text { education } \\
(<9) \\
M \pm \mathrm{SD}\end{array}$ & $\begin{array}{c}(N=57) \\
\text { Years of } \\
\text { education } \\
(>9)\end{array}$ & $P$ value \\
& $M \pm \mathrm{SD}$ & \\
\hline Somatic symptoms & $1.81 \pm 0.55$ & $1.74 \pm 0.54$ & NS** \\
Anxiety/insomnia & $1.82 \pm 0.69$ & $1.54 \pm 0.54$ & $.01^{*}$ \\
Social dysfunction & $2.30 \pm 0.49$ & $2.20 \pm 0.43$ & NS \\
Severe depression & $1.57 \pm 0.79$ & $1.29 \pm 0.50$ & $.01^{*}$ \\
\hline Total score & $1.88 \pm 0.53$ & $1.70 \pm 0.41$ & $.03^{*}$ \\
\hline${ }^{*} P<.05 ; N=144$. & & & \\
${ }^{* *}$ NS: not significant. & & &
\end{tabular}

depressed than males [15-18]. However, when gender differences were investigated in another measure of depression using the CES-D scale, they were not significant. Both genders in this scale presented a higher level than that found in normal populations and should be considered as depressed according to Fountoulakis et al. [36]. A possible explanation regarding the differential results in the GHQ28 and the CES-D scales is that although the two measures may be comparable regarding parts of their content, actually they measure different aspects of depression. Namely, the GHQ-28 severe depression subscale includes items on suicidal thoughts, which are not included in the CES-D scale. Thus, although men and women in our sample reported being depressed, they seemed to differ regarding the degree of endorsed suicidal ideas, and so we may suggest that women indicated more symptoms of "suicidal depression." Further, female patients reported being more anxious in comparison to males. This finding is also in agreement with several studies indicating that women present a higher prevalence of trait anxiety $[15,18]$. As in the above case of measures of depression, differential values were observed between the 
STAI II and the GHQ-28 anxiety/insomnia subscale. In this case, gender differences were found in the STAI II scale, as women reported higher levels of trait anxiety-a rather longstanding condition-while differences were not found in the GHQ-28 respective subscale. It is noteworthy that although these scales may present some content overlap, they do not measure the same dimensions of anxiety (e.g., the GHQ-28 anxiety/insomnia subscale includes items on sleep problems which are not included in the STAI II scale). It is suggested that both depression and anxiety measures need to be multiple as they are useful addressing different dimensions of the clinical entity.

Regarding age, although the differences found were generally expected, they were also illuminating as older patients reported falling behind in social activities and interests, and being more socially restricted and depressed. These findings are in agreement with several studies indicating that older patients present lower levels of physical well-being and higher levels of depression [17, 21-28].

Regarding differences in relation to education, end-stage renal disease (ESRD) patients with less than nine years of education seemed to evaluate their mental health in a more negative way and reported suffering from higher levels of anxiety/insomnia and severe depression. In overall, patients with lower socioeconomic profiles or lacking in education (which is generally taken as an indicator of social status) are reported in the literature facing problems in their psychological well-being, social relationships, and general health [19, 29-31].

In respect to marital status, divorced/widowed patients, compared to singles and married, evaluated less favourably their mental health and reported a higher level of depression with suicidal thoughts. On the basis of these findings, married patients seem to experience a better QoL. Similar evidence in the literature indicates that the status of marriage in these patients may be significantly correlated to an enhanced physical well-being and emotional health [26].

Investigating the effect of sociodemographic variables on the mental health of two groups separately, interesting and important findings are observed. More specifically, in the group of HD patients, females seem to face many difficulties in their mental health with more somatic symptoms and social dysfunction. Females also present more trait anxiety in comparison to males. With regards to age and marital status, older ( $>45$ years) and divorced/widowed HD patients appear more depressive. On the contrary, married HD patients evaluate their mental health positively.

In the group of PD patients, females present more state anxiety. Concerning age, older ( $>45$ years) PD patients have more somatic symptoms, restrictions in their social life, and more depression.

These results provide useful indications that certain variables referring to the patient's sociodemographic profile may affect favourably or unfavourably his/her mental health. The findings support evidence in the literature indicating that sociodemographic factors may to some extent contribute to the explanation of mental health and QoL [3941]. According to Sprangers et al. [42], independent of the kind of illness, being female, older, less educated, and living
TABle 5: Mean scores \pm SD of GHQ-28 health subscales. Oneway ANOVA showing differences among singles, married, and divorced/widowed.

\begin{tabular}{|c|c|c|c|c|}
\hline $\begin{array}{l}\text { GHQ-28 } \\
\text { subscales }\end{array}$ & $\begin{array}{c}(N=25) \\
\text { Single } \\
M \pm \mathrm{SD}\end{array}$ & $\begin{array}{c}(N=108) \\
\text { Married } \\
M \pm \mathrm{SD}\end{array}$ & $\begin{array}{c}(N=11) \\
\text { Divorced/ } \\
\text { Widowed } \\
M \pm \mathrm{SD}\end{array}$ & $P$ value \\
\hline $\begin{array}{l}\text { Somatic } \\
\text { symptoms }\end{array}$ & $1.91 \pm 0.54$ & $1.74 \pm 0.54$ & $1.94 \pm 0.57$ & NS** \\
\hline $\begin{array}{l}\text { Anxiety/ } \\
\text { insomnia }\end{array}$ & $1.74 \pm 0.60$ & $1.70 \pm 0.65$ & $1.76 \pm 0.78$ & NS \\
\hline $\begin{array}{l}\text { Social } \\
\text { dysfunction }\end{array}$ & $2.29 \pm 0.38$ & $2.24 \pm 0.48$ & $2.44 \pm 0.52$ & NS \\
\hline $\begin{array}{l}\text { Severe } \\
\text { depression }\end{array}$ & $1.32 \pm 0.32$ & $1.41 \pm 0.66$ & $2.19 \pm 1.14$ & $.00^{*}$ \\
\hline Total score & $1.82 \pm 0.38$ & $1.77 \pm 0.49$ & $2.08 \pm 0.64$ & NS \\
\hline
\end{tabular}

without a partner is connected with a lower QoL. This is an important reference which shows the strong relation between specific sociodemographic factors and QoL. With regards to the main hypothesis of the study, it is recognized that being male patient, younger, more educated, and married relates to a better mental health with less depressive and anxiety symptoms, giving in this way emphasis to the importance of family and high educational level. Consequently, our research hypothesis is confirmed.

In overall, our findings provide evidence which can be useful to health professionals and managers of health services offered to patients with CRF. Tailored interventions can be developed to support female but also male patients, those who are older, less educated, living alone, depressed, and anxious, in an effort to address issues of compromised mental health.

Concerning limitations in the study, it is noted that patients were recruited from three renal units and were a convenience sample. Thus, it was not possible to have an adequate control on demographic or clinical variables. Evidence provided by the results of this study can be further extended by the control of the above variables and the use of even larger samples. Limitations may also include the lack of pre-ESRD data as well as the fact that we did not investigate the effect of duration of disease and treatment on patients' mental health.

\section{Conclusions}

The main focus of the present study was to examine in a group of chronic renal disease patients differences referring to self-reported mental health, depression, and anxiety, after controlling for gender, age, levels of education, and marital status.

In the present study, our hypothesis is confirmed, that is being male, younger, more educated, and married appeared to have a favorable effect on several aspects of the patients' mental health. 


\section{Acknowledgments}

The author would like to thank the patients for their participation in the study and acknowledge the support given by the health professionals and the administration personnel of the dialysis participating units.

\section{References}

[1] J. Nilsson, A. K. M. M. Rana, and Z. N. Kabir, "Social capital and quality of life in old age: results from a cross-sectional study in rural Bangladesh," Journal of Aging and Health, vol. 18 , no. 3, pp. 419-434, 2006.

[2] G. Borglin, U. Jakobsson, A. K. Edberg, and I. R. Hallberg, "Older people in Sweden with various degrees of present quality of life: their health, social support, everyday activities and sense of coherence," Health and Social Care in the Community, vol. 14, no. 2, pp. 136-146, 2006.

[3] S. Demura and S. Sato, "Relationships between depression, lifestyle and quality of life in the community dwelling elderly: a comparison between gender and age groups," Journal of Physiological Anthropology and Applied Human Science, vol. 22, no. 3, pp. 159-166, 2003.

[4] R. Gokal, "Quality of life," in The Textbook of Peritoneal Dialysis, R. Gokal, R. Khanna, R. Th. Krediet, and E. Nolph, Eds., Kluwer Academic Publishers, Dordrecht, The Netherlands, 1994.

[5] R. Gokal, "Quality of life in patients undergoing renal replacement therapy," Kidney International, no. 40, pp. S-23S-27, 1993.

[6] P. L. Kimmel, R. A. Peterson, K. L. Weihs et al., "Aspects of quality of life in hemodialysis patients," Journal of the American Society of Nephrology, vol. 6, no. 5, pp. 1418-1426, 1995.

[7] K. W. Griffin, "Comparison of quality of life in haemodialysis and peritoneal dialysis patients," in Advances in Peritoneal Dialysis, R. Khanna, Ed., Peritoneal Dialysis Publications, Toronto, Canada, 1994.

[8] A. J. Christensen and S. L. Ehlers, "Psychological factors in end-stage renal disease: an emerging context for behavioral medicine research," Journal of Consulting and Clinical Psychology, vol. 70, no. 3, pp. 712-724, 2002.

[9] M. Ginieri-Coccossis and P. Theofilou, "Quality of life and health locus of control in renal disease: comparison of haemodialysis versus peritoneal dialysis patients," in Proceedings of the Conference on Patient Reported Outcomes in Clinical Practice, Budapest, Hungary, 2007, abstract R1232.

[10] C. Karamanidou, P. Theofilou, M. Ginieri-Coccossis, C. Synodinou, and G. Papadimitriou, "Anxiety, depression and health beliefs in end-stage renal disease (ESRD) patients," in Proceedings of the 17th European Congress of Psychiatry, Lisbon, Portugal, 2009, abstract R38.

[11] M. Ginieri-Coccossis, P. Theofilou, C. Synodinou, V. Tomaras, and C. Soldatos, "Quality of life, mental health and health beliefs in haemodialysis and peritoneal dialysis patients: investigating differences in early and later years of current treatment," BMC Nephrology, vol. 9, no. 1, article 14, 2008.

[12] P. Theofilou, "Psychiatric disorders in chronic periodical haemodialysis," Vima Asklipiou, vol. 9, pp. 420-440, 2010.

[13] P. Theofilou and E. Panagiotaki, "Factors affecting quality of life in patients with end-stage renal disease," Nursing, vol. 49, pp. 174-181, 2010.

[14] P. Theofilou, "Quality of life, mental health and health beliefs: comparison between haemodialysis and peritoneal dialysis patients," Interscientific Health Care, vol. 2, pp. 171-176, 2010.
[15] I. Vazquez, F. Valderrabano, I. Fort, R. Jofre, J. M. LopezGomez, and F. Moreno, "Differences in health-related quality of life between male and female haemodialysis patients," Nefrologia, vol. 24, pp. 167-178, 2004.

[16] S. S. Gottlieb, M. Khatta, E. Friedmann et al., "The influence of age, gender, and race on the prevalence of depression in heart failure patients," Journal of the American College of Cardiology, vol. 43, no. 9, pp. 1542-1549, 2004.

[17] G. Oikonomidou, D. Zlatanos, H. Vayopoulos, and H. Hatzidimitriou, "Depression in patients with chronic renal failure," Dialysis Living, vol. 14, pp. 22-32, 2005.

[18] F. Di Marco, M. Verga, M. Reggente et al., "Anxiety and depression in COPD patients: the roles of gender and disease severity," Respiratory Medicine, vol. 100, no. 10, pp. 1767-1774, 2006.

[19] P. Rebollo, F. Ortega, J. M. Baltar et al., "Health-related quality of life (HRQOL) in end stage renal disease (ESRD) patients over 65 years," Geriatric Nephrology and Urology, vol. 8, no. 2, pp. 85-94, 1998.

[20] J. M. Gil Cunqueiro, M. J. García Cortés, J. Foronda et al., "Health-related quality of life in elderly patients in haemodialysis," Nefrologia, vol. 23, no. 6, pp. 528-537, 2003.

[21] T. Apostolou and R. Gokal, "Quality of life after peritoneal dialysis," in The Textbook of Peritoneal Dialysis, R. Gokal, R. Khanna, R. Th. Krediet, and E. Nolph, Eds., Kluwer Academic Publishers, Dordrecht, The Netherlands, 2000.

[22] N. G. Kutner, R. Zhang, H. Barnhart, and A. J. Collins, "Health status and quality of life reported by incident patients after 1 year on haemodialysis or peritoneal dialysis," Nephrology Dialysis Transplantation, vol. 20, no. 10, pp. 2159-2167, 2005.

[23] N. Dimkovic and D. G. Oreopoulos, "Chronic peritoneal dialysis in the elderly," Seminars in Dialysis, vol. 15, no. 2, pp. 94-97, 2002.

[24] A. Iacovides, K. N. Fountoulakis, E. Balaskas et al., "Relationship of age and psychosocial factors with biological ratings in patients with end-stage renal disease undergoing dialysis," Aging-Clinical and Experimental Research, vol. 14, no. 5, pp. 354-360, 2002.

[25] E. Moshopoulou and E. Savidaki, "Psychosocial profile of haemodialysis patients. Approach-intervention," Dialysis Living, vol. 7, pp. 1-5, 2003.

[26] C. K. Chiang, Y. S. Peng, S. S. Chiang et al., "Health-related quality of life of hemodialysis patients in Taiwan: a multicenter study," Blood Purification, vol. 22, no. 6, pp. 490-498, 2004.

[27] J. Tyrrell, L. Paturel, B. Cadec, E. Capezzali, and G. Poussin, "Older patients undergoing dialysis treatment: cognitive functioning, depressive mood and health-related quality of life," Aging \& Mental Health, vol. 9, no. 4, pp. 374-379, 2005.

[28] I. A. Vasilieva, "Quality of life in chronic hemodialysis patients in Russia," Hemodialysis International, vol. 10, no. 3, pp. 274278, 2006.

[29] M. Ellinikou and A. Zissi, "Quality of life and chronic illnesses. Prognostic variables for the psychosocial rehabilitation of the patients with chronic illness," Medicine, vol. 82, pp. 124-131, 2002.

[30] R. Sesso, J. F. Rodrigues-Neto, and M. B. Ferraz, "Impact of socioeconomic status on the quality of life of ESRD patients," American Journal of Kidney Diseases, vol. 41, no. 1, pp. 186195, 2003.

[31] I. Vázquez, F. Valderrábano, R. Jofré et al., "Psychosocial factors and quality of life in young hemodialysis patients with low comorbidity," Journal of Nephrology, vol. 16, no. 6, pp. 886-894, 2003. 
[32] D. P. Goldberg, Manual of the General Health Questionnaire, NFER-Nelson, Windsor, UK, 1978.

[33] G. Garyfallos, A. Karastergiou, A. Adamopoulou et al., "Greek versions of the General Health Questionnaire: accuracy of translation and validity," Acta Psychiatrica Scandinavica, vol. 84, no. 4, pp. 371-378, 1991.

[34] L. S. Radloff, "The CES-D scale: a self-report depression scale for research in the general population," Applied Psychological Measurement, vol. 1, pp. 385-401, 1977.

[35] D. Hann, K. Winter, and P. Jacobsen, "Measurement of depressive symptoms in cancer patients: evaluation of the center for epidemiological studies depression scale (CES-D)," Journal of Psychosomatic Research, vol. 46, no. 5, pp. 437-443, 1999.

[36] K. Fountoulakis, A. Iacovides, S. Kleanthous et al., "Reliability, validity and psychometric properties of the Greek translation of the Center for Epidemiological Studies-Depression (CESD) Scale," BMC Psychiatry, vol. 1, article 3, 2001.

[37] G. O. Spielberger, The State-Trait Anxiety Inventory, Consulting Psychologists Press, Palo Alto, Calif, USA, 1970.

[38] A. Liakos and S. Giannitsi, "Reliability and validity of the Greek state-trait anxiety inventory of spielberger," Egephalos, vol. 21, pp. 71-76, 1984

[39] R. Arnold, A. V. Ranchor, R. Sanderman, G. I. J. M. Kempen, J. Ormel, and T. P. B. M. Suurmeijer, "The relative contribution of domains of quality of life to overall quality of life for different chronic diseases," Quality of Life Research, vol. 13, no. 5, pp. 883-896, 2004.

[40] P. Theofilou, M. Ginieri-Coccossis, and C. Synodinou, "Sociodemographic variables, health beliefs, psychopathological symptoms: influence factors of quality of life in patients with chronic renal failure," in Clinical Psychology and Health Psychology-Research and Practice, G. Koulierakis, A. Pashali, V. Rotsika, and M. Ginieri-Coccossis, Eds., Papazisi, Athens, Greece, 2010.

[41] P. Theofilou, "The role of sociodemographic factors in health-related quality of life of patients with end-stage renal disease," International Journal of Caring Sciences, vol. 4, no. 1, pp. 40-50, 2011.

[42] M. A. G. Sprangers, E. B. De Regt, F. Andries et al., "Which chronic conditions are associated with better or poorer quality of life?" Journal of Clinical Epidemiology, vol. 53, no. 9, pp. 895-907, 2000. 


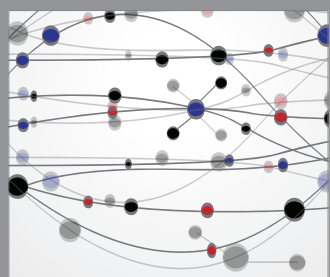

The Scientific World Journal
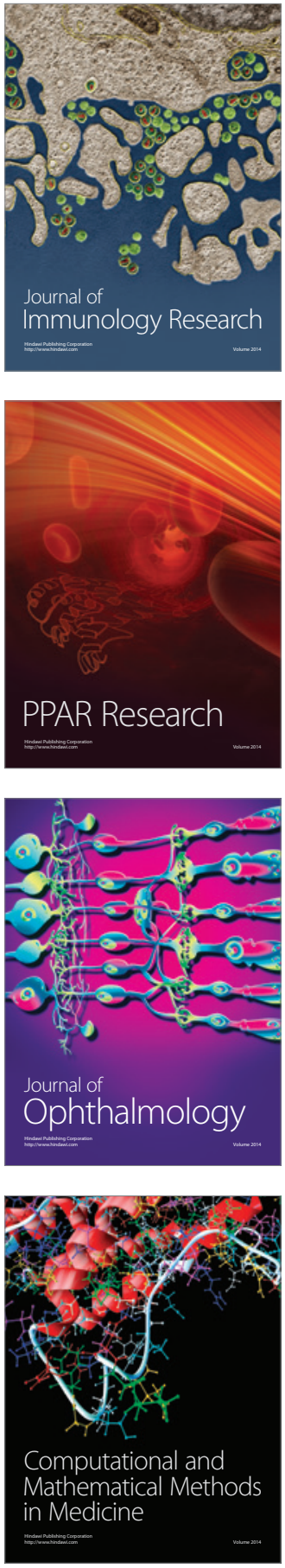

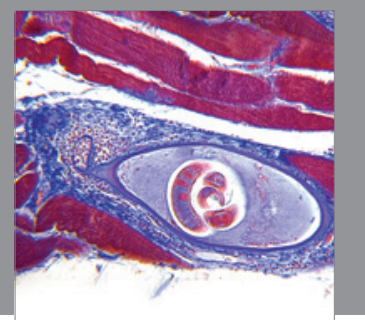

Gastroenterology

Research and Practice
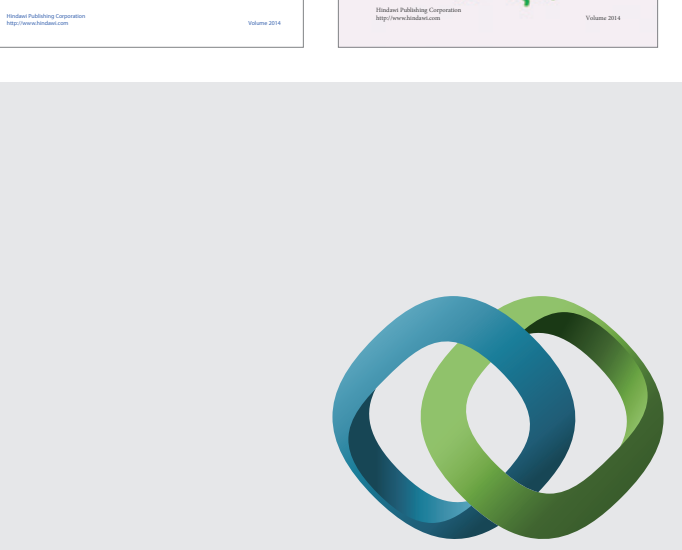

\section{Hindawi}

Submit your manuscripts at

http://www.hindawi.com
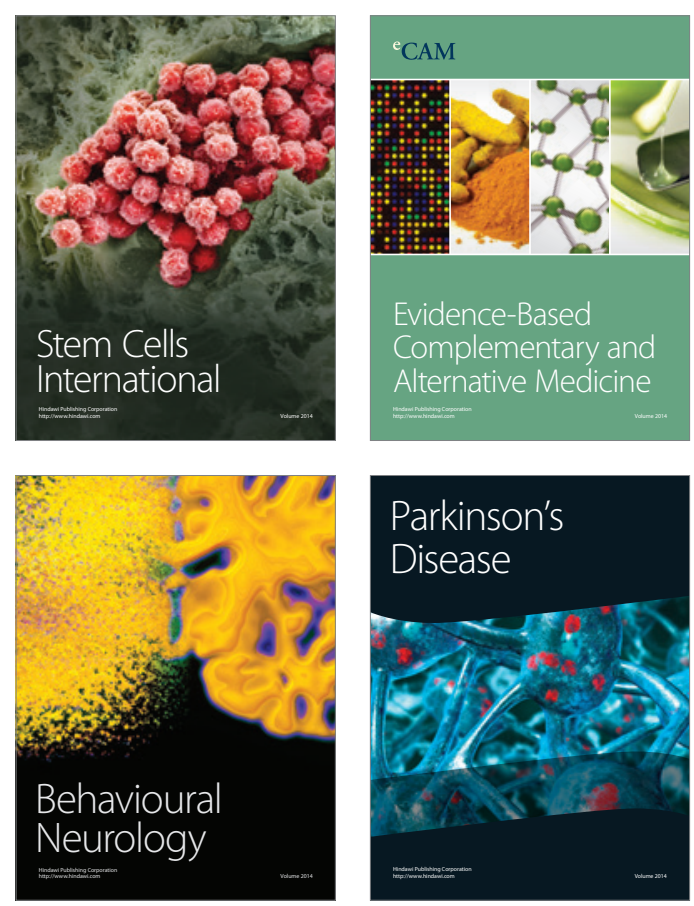

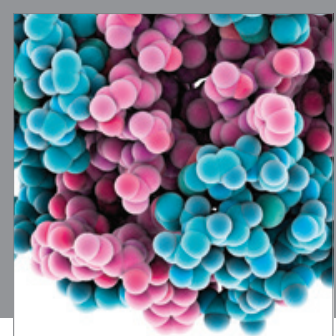

Journal of
Diabetes Research

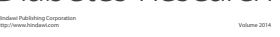

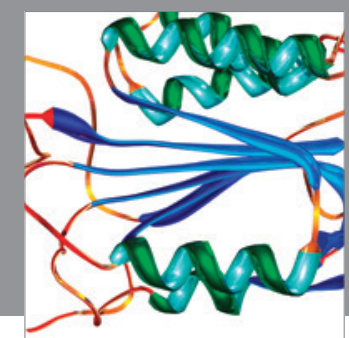

Disease Markers
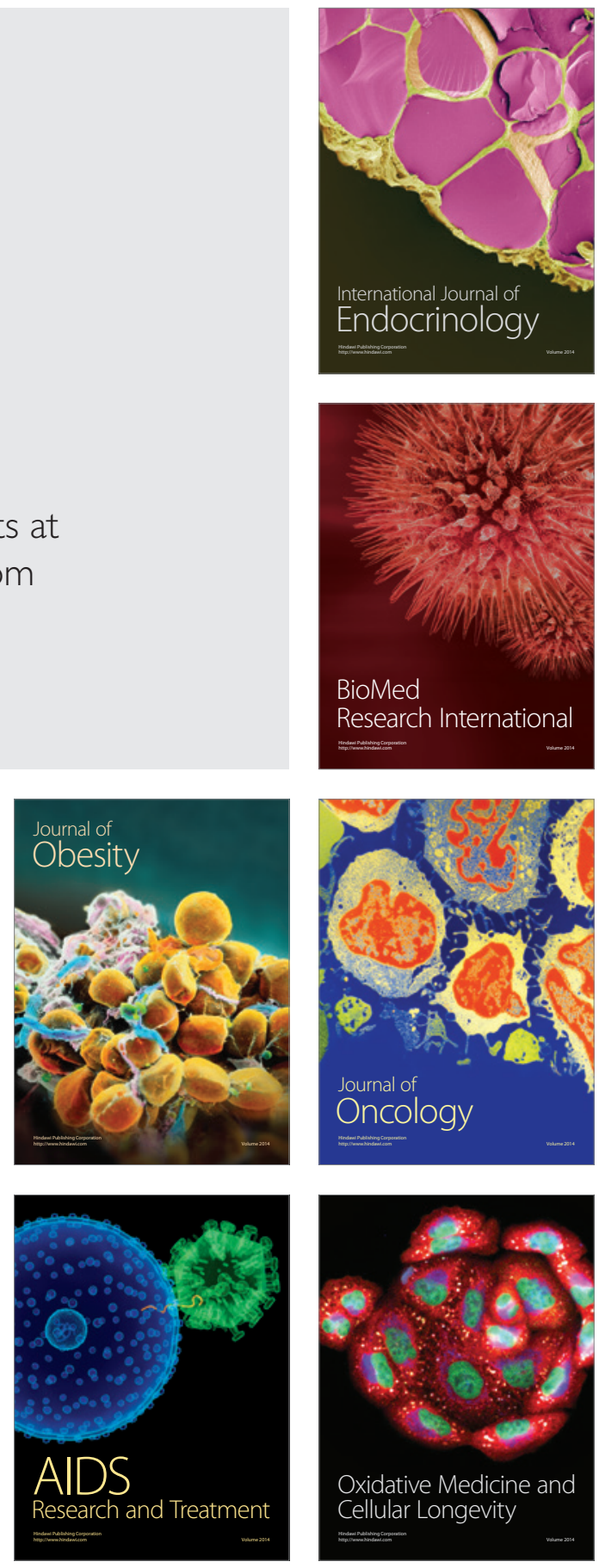